\title{
高精度大数据重塑古代生物多样性记录
}

\author{
殷鸿福 \\ 中国地质大学(武汉), 生物地质与环境地质国家重点实验室, 武汉 430074 \\ E-mail: hfyin@cug.edu.cn
}

\section{High-resolution big data reshape ancient biodiversity records}

\author{
Hongfu Yin \\ State Key Laboratory of Biogeology and Environmental Geology, China University of Geosciences (Wuhan), Wuhan 430074, China \\ E-mail: hfyin@cug.edu.cn
}

doi: 10.1360/TB-2020-0614

21 世纪的地球科学主题是研究地球各圈层相互作用 的地球系统科学. 生物圈演化与地球演化基本同步, 其研 究对象有机界相对于无机界演化快速、反应灵敏, 因此对 地球系统科学研究十分重要. 迄今对生物圈演化的研究集 中在距今 5.4 亿年前的显生宙. 依据古生物数据库建立的 几个显生宙生物演化曲线 ${ }^{[1 \sim 3]}$ 已经揭示了生物的盛衰史及 其转折点——起源、辐射和灭绝. 但是迄今的工作都遇到 了同样的瓶颈: 由于化石采集的不完备性和时间记录、化 石鉴定的不精确性, 导致所建立的曲线比较粗略 (时间精 度为 $8 \sim 11 \pm 2.4 \sim 3.2 \mathrm{Ma}$ ), 不能精确描述生物演化和卡定突 发性事件, 并难于与较精确的地球化学曲线相对比, 因而 在恢复地球历史变迁、进而预测未来方面受到限制.

Fan等人 ${ }^{[4]}$ 报道的GBDB(Geobiodiversity Database)古 生代至中三叠世数据库在这方面有所突破, 表现在以下几 方面(图1): (1) 资料基础完备, 可靠性高. 研究基于3112条 地层剖面、11268个海洋生物物种、116060个地层层位, 而 且化石清单经过专家审定; (2) 此数据库虽以中国为主, 但由于组成中国的各板块的地史分布, 基本上代表了显生 宙时的东半球自冈瓦纳南部至北方区北部的情况(文献[4] 的图 S3), 且可与以往以西半球为主的诸曲线互相补充对 照; (3) 更重要的是, 为了改进时间记录不精确性, 他们采

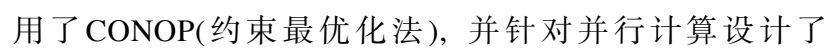
SAGA混合算法(模拟退火算法 simulated annealing和遗传 算法 genetic algorithm), 形成了CONOP.SAGA方法, 使其 古生代至中三叠世的时间划分到一万一千多个时间段, 其 平均时间精度达到约 $2.6 \pm 1.49$ 万年, 比前人的时间精度提 高了 400 余倍. 这大大细化了该时间段生物演化的研究, 并加强了与地球环境演变对比的潜力.
与包括Sepkoski ${ }^{[1]} 、$ Alroy等人 ${ }^{[2]} 、$ Bambach $^{[3]}$ 在内的以 往成果相比, Fan等人 ${ }^{[4]}$ 利用GBDB所绘制的古生代至三叠 纪生物多样性曲线, 在晚奥陶世、泥盆纪F.-F. (文献[4]中前 延至中-晚泥盆世)及二叠纪末 3 次大灭绝方面大体相似, 在 生物辐射方面则有差异. 其中, 奥陶纪大辐射从寒武纪末 即已开始, 比以往提早了 2 千万年; 显现了一个早志留世的 辐射, 是以往没有的; 以往曲线显示了晚石炭世至早中二 叠世的较小辐射, 此次曲线则显示其幅度更大、时限更长, 可与奥陶纪大辐射媲美, 并且延伸至晚二叠世而没有中二 叠世末的灭绝. 这些变动值得我们注意. 但是文献[4]中 “二 叠纪末大灭绝”延至251.32(251.95 0.63) Ma, 已进人三叠纪 范围(文献[4]中表 $\mathrm{S} 2$, H. parvus 时间为 $251.902 \mathrm{Ma}$ ), 似应称 为 “二叠-三叠纪之交大灭绝”, 这样称呼亦符合野外实况.

Fan等人 ${ }^{[4]}$ 将 $\mathrm{GBDB}$ 生物多样性曲线与显生宙同一时 间段中多种反映地球环境变化的代用标志曲线相对比, 试 图从生物与环境协同演化的角度论述生物多样性变化的 外因机制. 对比结果是, 大气 $\mathrm{CO}_{2}$ 浓度与生物多样性的长 期曲线有某种相似性，但用差分法(first difference)去除时 间序列趋势后，显示两者并无显著因果关系(文献[4]中图 4(F)和5). 其他代用标志曲线亦未能显示与生物多样性曲 线的可对比性. 搞清楚古生代气候与构造活动 (含大陆漂 移) 与生物多样性的关系还有很长一段路要走, 但Fan等 人 $^{[4]}$ 的尝试是值得赞赏的.

古生物学已经有几百年的历史. GBDB在传统的分类 学和生物地层学基础上, 采用创新的方法和大数据、高性 能计算(天河二号超级计算机)、人工智能算法, 使我国古生 物数据库研究走到国际前列. 它给我们的启示是, 古老的 学科可以焕发青春, 其途径是开拓创新和交叉融合. 


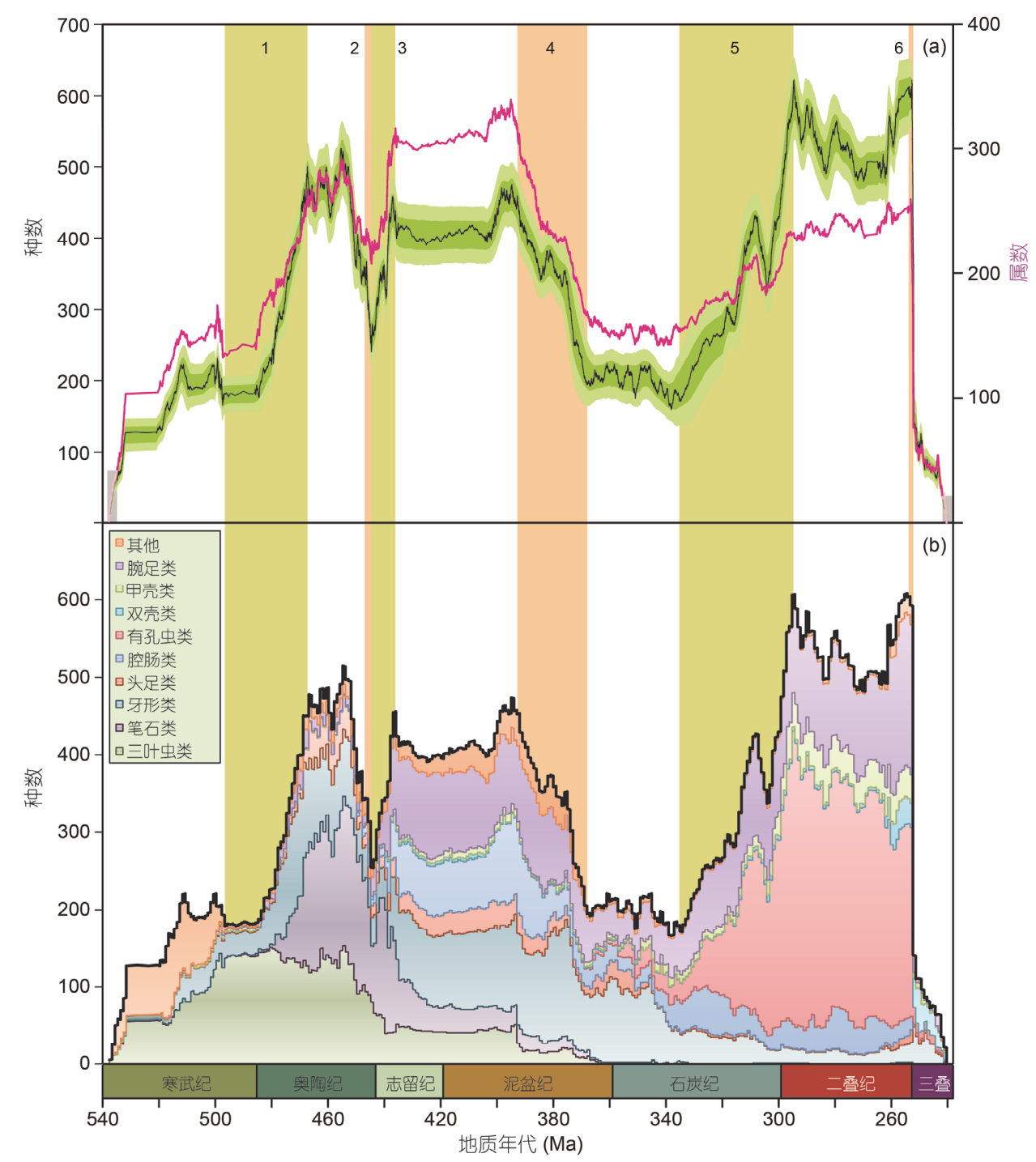

图 1 古生代属种多样性变化曲线(a)和 10 个主要化石类群的种级多样性(b $)^{[4]}$. 淡绿色和暗绿色阴影分别代表 500 次运算产生的 $1 \sigma$ 和 $2 \sigma$ 偏差 范围, $2 \sigma$ 偏差范围大约相当于 $95 \%$ 的置信区间. 1 , 奥陶纪生物大辐射; 2 , 奥陶纪末生物大灭绝; 3 , 早志留世生物辐射; 4 , 中-晚泥盆世生物多样 性下降; 5 , 晚石炭世-早二叠世生物大辐射; 6 , 二叠纪末生物大灭绝

Figure 1 General trajectories of Paleozoic genus and species diversity and species diversity for 10 major fossil groups ${ }^{[4]}$. (a) Genus(red) and species(green) diversity. (b) Species diversity. The light and dark green shading in (a) represent $1 \sigma$ and $2 \sigma$ standard deviations, respectively, which are based on 500 bootstrap runs. $2 \sigma$ approximately equals the $95 \%$ confidence interval. 1, Great Ordovician biodiversification event; 2 , end-Ordovican mass extinction; 3, early Silurian radiation; 4, Middle to Late Devonian diversity decline; 5, late Carboniferous-early Permian biodiversification event; 6 , end-Permian mass extinction

\section{参考文献}

1 Sepkoski J J Jr. A Compendium of Fossil Marine Animal Genera. Ithaca: Paleontological Research Institution, 2002

2 Alroy J, Aberhan M, Bottjer D J, et al. Phanerozoic trends in the global diversity of marine invertebrates. Science, 2008, 321: 97-100

3 Bambach R K. Phanerozoic biodiversity mass extinctions. Annu Rev Earth Planet Sci, 2006, 34: 127-155

4 Fan J X, Shen S Z, Erwin D H, et al. A high-resolution summary of Cambrian to Early Triassic marine invertebrate biodiversity. Science, 2020, 367: $272-277$ 